\title{
Study on the Evaluation Factors of Full-time Postgraduate Course Study_Empirical Research Based on SEM
}

\author{
Hu Chenyue, Hong Lan, Liu Chunyan \\ School of Computer and Information Science, Chongqing Normal University, Chongqing, China \\ Email address: \\ 1072717904@qq.com (Hu Chenyue),2248619140@qq.com (Hong Lan),804627889@qq.com (Liu Chunyan)
}

\section{To cite this article:}

Hu Chenyue, Hong Lan, Liu Chunyan. Study on the Evaluation Factors of Full-time Postgraduate Course Study_Empirical Research Based on SEM. Science Innovation. Vol. 9, No. 3, 2021, pp. 81-85. doi: 10.11648/j.si.20210903.11

Received: January 29, 2021; Accepted: May 10, 2021; Published: May 24, 2021

\begin{abstract}
Postgraduate course study is a way to improve the quality of postgraduate education. Taking course study evaluation as the starting point, understand the factors that affect postgraduate course study evaluation, and explore effective ways to improve the effect of postgraduate course study. In the context of the expansion of full-time postgraduate enrollment, in order to more effectively promote the study of postgraduate courses, this article attempts to take full-time postgraduates from three universities in the southwest region as the survey object, and through the systematic literature review of factors affecting course evaluation at home and abroad, And combined with the actual situation of domestic higher education, select three dimensions that affect the evaluation of postgraduate courses as research indicators, analyze the factors that affect the evaluation of full-time postgraduate courses, construct a corresponding structural equation model based on the evaluation indicators, and analyze the weight of each influencing factor And make relevant suggestions. The research results show that learning gain is the most significant factor influencing the evaluation of full-time postgraduates' courses; different postgraduate grades believe that the importance of each dimension in the classroom is different; classroom atmosphere is also particularly important in postgraduate course learning.
\end{abstract}

Keywords: Postgraduates, Course Evaluation, Influencing Factors, Structural Equation Model

\section{基于SEM的硕士研究生课程学习评价因素实证研究}

胡陈粤, 洪岗, 刘春燕

重庆师范大学计算机与信息科学学院, 重庆, 中国

邮箱

1072717904@qq.com（胡陈粤），2248619140@qq.com（洪岗）,804627889@qq.com（刘春燕）

摘要: 研究生课程学习是提高研究生教育质量的途径, 以课程学习评价为切入点, 了解影响研究生课程学习评价的因 素, 探讨提高研究生课程学习效果的有效途径。在全日制硕士研究生扩大招生的背景下，本文试图以西南地区三所高 校全日制硕士研究生为调查对象, 分析影响全日制硕士研究生课程评价的因素, 根据评价指标构建结构方程模型分析 各影响因素的权重并提出相关建议。研究结果表明, 学习收获是影响全日制硕士研究生课程评价最为显著的因素; 研 究生年级不同, 其认为各维度在课堂上的重要程度不同; 课堂氛围在研究生的课程学习中也尤为重要。

关键词: 硕士研究生, 课程评价, 影响因素, 结构方程模型 


\section{1. 引言}

《国家中长期教育改革和发展规划纲要》明确提出: 要 全面提高高等教育质量, 全面推进教育教学改革[1]。研究生 作为国家培养的高层次人才, 其课程学习评价因素的探究, 不仅可以衡量研究生教育质量, 同时也是推进教育教学改革 的关键[2]。党的十九大报告指出“优先发展教育事业。建设 教育强国是中华民族伟大复兴的基础工程, 必须把教育事业 放在优先位置。”随着教育事业的不断发展, 研究生的培养 也引起了社会的高度关注。在研究生日益扩招的背景下, 怎 样保证研究生课程教学质量是研究生教育的根本, 高校课程 评价也引起了前所未有的重视和关注。研究生课程学习的效 果与质量, 最有发言权的应是研究生自己, 所以从研究生的 视角来进行课程评价对提高教育质量具有重大意义 [3]。

\section{2. 研究背景与研究假设}

\section{1. 研究背景}

目前, 国内流行的教学评价是学生仅对教师本身以及 其课堂教学质量进行简短的评价, 评价主体是学生, 评价 对象是授课教师而非对课程整体进行评价。国内学者关于
课程评价的相关研究主要设计到对课程评价指标体系的 构建、课程评价的现状分析、课程评价存在的问题等方面, 而对高校课程评价较少, 尤其是硕士研究生课程评价的相 关研究 [4]。

相对于国内而言, 国外对于影响课程评价因素的研究 则相对较多, 美国学生评价课程设计本课程的学习提高学 生的知识和专业水平、课本和其他阅读材料的实用性、课 程目标和评分制度是否清晰地阐释、作业量、课程内容的 条理性、课堂气氛的活跃性、教师板书和幻灯片内容的简 洁性、考试内容与教学内容的紧密性、教师评分的公正性、 作业难度的适合性及设计的合理性、考试难度设及设计、 作业和考试是否及时批改 [5]。

\section{2. 研究假设}

本文试图以全日制硕士研究生为调查对象, 对影响硕 士研究生课程评价的因素进行调查分析。通过对国内外影 响课程评价的因素作系统的文献梳理, 并结合国内高等教 育实际情况, 选取影响硕士研究生课程评价的三个维度作 为调研指标: (1) 教师教学模式; (2) 学生认知能力; (3) 课堂氛围。构建硕士研究生课程学习评价因素结构 方程模型, 如图1所示。

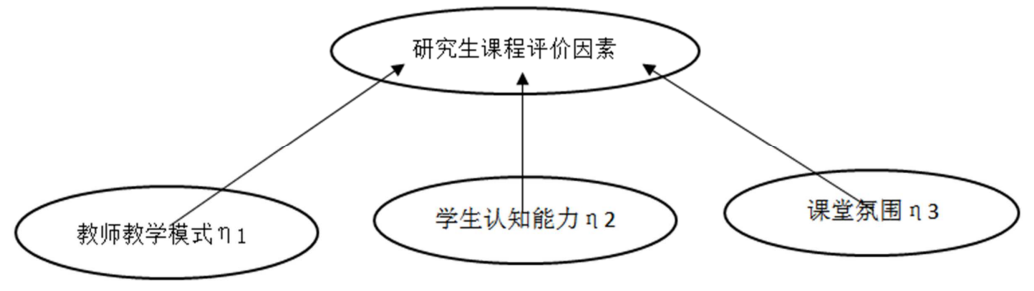

图1 硕士研究生课程学习评价因素结构方程模型。

在该假设模型中, 研究生课程评价因素 $\xi$ 为因变量, 而教师教学模式 $\eta 1$ 、学生认知能力力 $\eta 2$ 、课堂氛围 $\eta 3$ 均为 自变量。同时提出以下假设:

$\mathrm{H} 1$ : 教师教学模式对硕士研究生课程学习评价有正向 显著影响;

$\mathrm{H} 2$ : 学生认知能力对硕士研究生课程学习评价有正向 显著影响; 影响。

$\mathrm{H} 3$ : 课堂氛围对硕士研究生课程学习评价有正向显著

表1 硕士研究生课程学习评价因素指标体系变量表.

\begin{tabular}{lll}
\hline 潜变量 & 显变量 & 含义 \\
\hline & 课堂计划与组织Y1 & 教师对课程教学内容的计划与组织 \\
& 课程进度安排Y2 & 教师对课程教学总体进度安排 \\
& 教学方式Y3 & 教师授课的教学方式 \\
教师教学模式 $\eta 1$ & 教学方法Y4 & 教师授课的教学方法 \\
& 教学风格Y5 & 教师授课的表现风格 \\
& 作业合理性设计Y6 & 教师对作业量及其难度设计的合理性 \\
& 成绩评定Y7 & 学生成绩评定标准的合理性及公正性 \\
& 学习水平Y8 & 学生的学习能力及接受知识的能力 \\
学生认知能力 $\eta 2$ & 学习收获Y9 & 学生在课程学习中的收获 \\
& 努力与投入度Y10 & 学生自身对课程的投入度及努力程度 \\
& 师生互动Y11 & 师生间互动的方式、方法 \\
课堂氛围 $\eta 3$ & 课堂交流Y12 & 课堂上学生之间、师生之间交流的情况 \\
\hline
\end{tabular}

\section{3. 研究设计}

\section{1. 硕士研究生课程学习评价因素指标体系变量表}

在结构方程模型中, 不能准确、直接测量的变量称为 潜变量, 需要通过外界指标间接地去测量 [6]。该结构方程 模型中的三个维度由相应的外显指标展开测量。依据评价 指标的可操作性和导向型原则, 通过梳理中外相关研究文 献, 最终确定 3 个潜变量和 12 个因变量, 形成的硕士研究 生课程学习评价因素指标体系变量表, 如表1所示。 


\section{2. 数据的采集与处理}

根据硕士研究生课程学习因素评价指标体系变量表编制 “硕士研究生课程学习评价影响因素”调查问卷。问卷第一部 分是学生的基本信息, 包括性别、年龄、年级等; 第二部分 采用李克特量表5级量表计分, 由1“很不重要”到5“很重要”进 行设置 $[7,8]$ 。调研对象来自西南地区三所高校, 采用线上问 卷的方式，共发放230份问卷，回收问卷219份，剔除无效问 卷19份, 最终获得有效问卷200份, 问卷有效回收率为 $91.3 \%$ 。

\section{4. 实证分析}

\section{1. 问卷的信效度分析}

\subsection{1. 信度分析}

本研究信度采用Cronbach $\alpha$ 系数作为判断标准, 将有 效问卷导入SPSS 24.0软件中进行信度分析, 其计算结果如 表2所示。

表2 调查问卷的信度分析。

\begin{tabular}{lllll}
\hline 可靠性统计 & & & & \\
\hline & 整体问卷 & 教师教学模式 & 学生认知能力 & 课堂氛围 \\
\hline Cronbach $\alpha$ & 0.888 & 0.842 & 0.807 & 0.875 \\
\hline
\end{tabular}

由表 2 可知, 本调查中整体问卷以及问卷中各变量的 Cronbach $\alpha$ 信度系数均大于 0.8 , 各项均满足Cronbach $\alpha$ 值 $>0.7$, 可以判断出影响硕士研究生课程评价的因素调查 问卷的总体量表和各变量的分量表可信度较好, 各项之间 具有良好的内在一致性。

\subsection{2. 效度分析}

本研究效度采用探索因子分析法进行分析。为了考察 研究样本是否适合作因子分析, 对题项进行 KMO 和 Bartlete检验, 其结果如表3所示。
表3 调查问卷的KMO和Bartlete检验。

\begin{tabular}{lll}
\hline KMO 和 Bartlett 的检验 & & \\
\hline 取样足够度的 Kaiser-Meyer-Olkin 度量。 & $\mathbf{. 8 2 1}$ \\
\hline \multirow{2}{*}{ Bartlett 的球形度检验 } & 近似卡方 & 1279.745 \\
& $\mathrm{df}$ & 66 \\
& $\mathrm{Sig}$. & .000 \\
\hline
\end{tabular}

由表 3 可知, 本研究的 KMO值为 $0.821>0.8$, Bartlete 检验给出的相伴概率为 0.000 , 小于显著性水平 0.05 , 因此 认为相关系数矩阵与单位矩阵有显著性差异, 说明本研究 中的变量适合做因子分析。

\section{2. 结构方程模型分析}

上述分析表明该研究满足使用结构方程模型的基本 要求。基于上述假设, 结合问卷的 3 个潜变量和 12 个显变 量, 运用AMOS 24.0软件绘制硕士研究生课程学习评价因 素结构方程模型图。

1、变量违反估计鉴定、模型拟合指标鉴定

初始模型中变量的估计值均为小于 1 的正数, 表明变 量没有违反估计值。继续检验模型拟合度各指标值, 在模 型适配检验值中, 卡方值为 637.641 , 显著性概率值 $\mathrm{P}=0.000<0.05$, 拒绝虚无假设, 近似误差均方根RMSEA 值等于 $0.157>0.05$, AGFI值等于 $0.694<0.9$, GFI值等于 $0.800<0.9$, 表明初始假设模型与实际数据适配不理想, 需 要对模型进行进一步修正。

\section{2、模型的修正}

根据模型简要适配报表的修正建议, 增设e1-e2、e3-e4、 e4-e5、e1-e7、e9-e12等误差值项的共变关系, 修正模型后, 模型拟合报表如表4所示各项指标均达到适配标准，修正 后的模型图如图2所示:

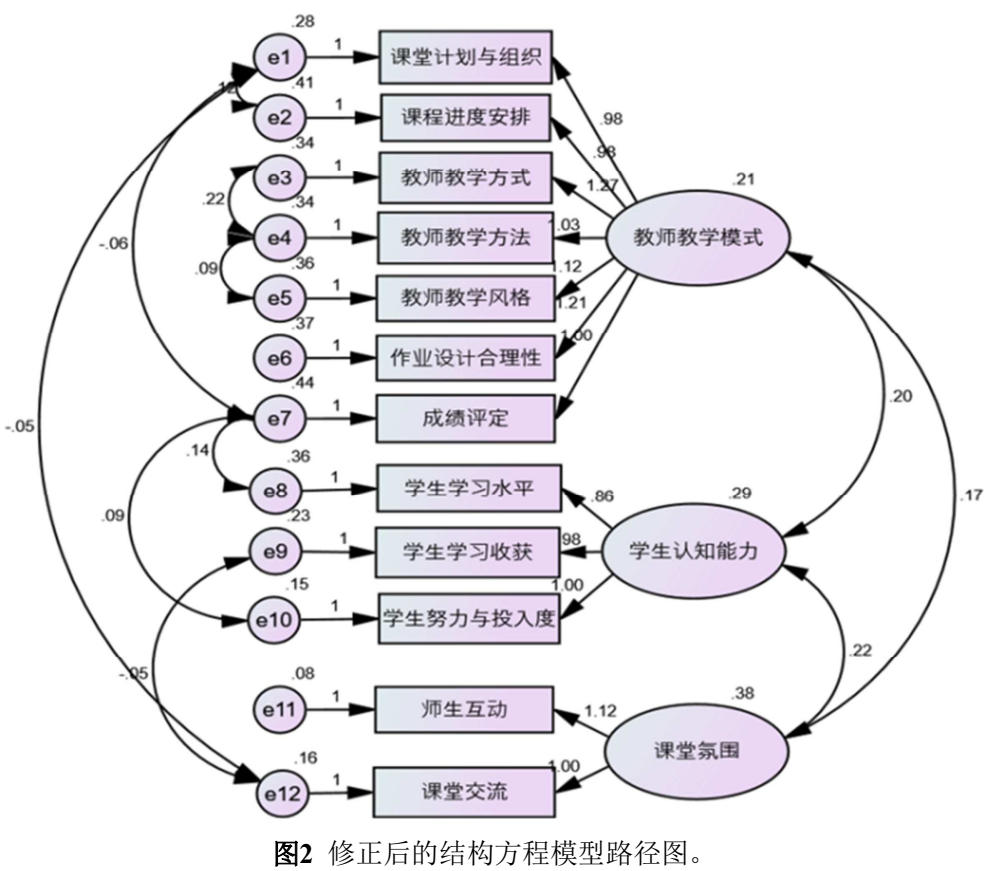


表4 模型适配度检验结果摘要表。

\begin{tabular}{llll}
\hline $\begin{array}{l}\text { 统计检验量适配 } \\
\text { 判断 }\end{array}$ & 检验结果数据 & 适配要求 & $\begin{array}{l}\text { 模型适配判 } \\
\text { 断 }\end{array}$ \\
\hline$\chi^{2} / \mathrm{df}$ & 2.578 & $<3$ & 是 \\
RMSEA & 0.078 & $<0.08$ & 是 \\
RMR & 0.031 & $<0.05$ & 是 \\
GFI & 0.921 & $>0.9$ & 是 \\
AGFI & 0.904 & $>0.9$ & 是 \\
CFI & 0.946 & $>0.9$ & 是 \\
IFI & 0.947 & $>0.9$ & 是 \\
TLI & 0.916 & $>0.9$ & 是 \\
PGFI & 0.508 & $>0.5$ & 是 \\
PNFI & 0.596 & $>0.5$ & 是 \\
PCFI & 0.616 & $>0.5$ & 是 \\
\hline
\end{tabular}

\section{5. 研究发现}

1、学生认知能力是影响学生课程评价的重要因素, 其中学生努力与投入度是最重要的影响因素

研究根据构建的硕士研究生课程学习评价因素模型 得出各级指标的权重以及样本得分, 如表5所示。硕士研 究生课程评价总体均分为4.19（满分为5）, 其三个维度 中, 教师教学模式的均分为 4.09 , 学生认知能力的均分为 4.26 , 课堂氛围的均分为 4.23 .

表5 硕士研究生课程学习评价因素得分表。

\begin{tabular}{llll}
\hline 课程总体评价 (4.19) & & & \\
\hline 教师教学模式 (4.09) & 课堂计划与组织 (3.83) & 课程进度安排 (3.93) & 教师教学方式 (4.32) 教师教学方法 (4.37) \\
& 教师教学风格 (4.15) & 作业设计合理性 (4.03) & 成绩评定 (4.03) \\
& 学生学习水平 (4.11) 学生学习收获 (4.31) & \\
学生认知能力 (4.26) & 学生努力与投入度 (4.36) & & \\
课堂氛围 $(4.23)$ & 师生互动 $(4.24)$ & 课堂交流 (4.22) & \\
\hline
\end{tabular}

从表5所分析的数据结果可以看出:

(1) 硕士研究生对课程总体的评价整体呈现良好。 硕士研究生对课程的总体评价均分达到了4以上, 也就相 当于达到了百分制的 80 分以上, 表明硕士研究生课程的安 排、设计与教学得到了学生的认可。

(2) 硕士研究生课程评价影响因素的三个维度中, 学生认知能力得分最高。相对于教师教学模式、课堂氛围 两个维度来说, 更多学生认为其本身的认知能力更重要, 其中学生的努力与投入度是最为显著的因素, 表明学生自 身对课程的态度更能够影响其学习的效果。

2、研究生个人背景在课程评价影响因素中的差异分 析

研究按照性别、年级、硕士类别对硕士研究生课程学 习评价因素得分进行独立性检验和单因素方差分析, 得出 结果如下:

(1) 按性别在各维度上的评分均值进行独立样本 T 检验, 从研究生课程评价影响因素在性别上的差异可以看 出, 教师教学模式、学生认知能力和课堂氛围的 $\mathrm{P}$ 值依次 是 $0.065 、 0.386 、 0.172$, 均大于 0.05 , 即表示研究生课程 评价影响因素在性别上没有显著差异。

(2) 按硕士研究生类别在各维度上的评分均值进行 独立样本 $\mathrm{T}$ 检验, 从研究生课程评价影响因素在硕士研究 生类别上的差异可以看出, 教师教学模式、学生认知能力、 课堂氛围的 $\mathrm{P}$ 值依次是 $0.725 、 0.086 、 0.079$, 均大于 0.05 , 即研究生课程评价影响因素在硕士研究生类别上无显著 性差异。

（3）按年级在各维度上的评分均值进行单因素方差 分析, 检验结果得出, 教师教学模式维度 $\mathrm{P}$ 值为 $0.075>0.05$, 学生认知能力维度 $\mathrm{P}$ 值为 $0.048<0.05$, 课堂氛围维度 $\mathrm{P}$ 值为 $0.751>0.05$ 。数据表明教师教学模式、课堂氛围两个维度 方差同质性均为显著, 即这两个因素在不同年级之间并无 差异; 学生认知能力维度的方差同质性不显著, 即该维度 在不同年级件有显著差异。对不同年级而言, 教师教学模
式和课堂氛围两个维度未达到显著差异, 学生认知能力维 度有显著差异。由此可见, 不同年级的硕士研究生认为学 生认知能力在课堂上的重要程度是不同的, 挖掘研究生认 知能力的年级特征, 并根据其进行因材施教对提高课程学 习效果尤为重要。

\section{6. 研究结论}

研究生的培养是我国教育关注的重点, 研究生教育是 高等教育的重要组成部分, 在研究生中培养拔尖人才是高 等教育的使命 [9]。基于以上的研究结果, 为了更有效促进 硕士研究生课程学习, 特提出以下对策建议:

1、重视学生学习收获, 提高学生学习积极性。

研究的数理结果分析表明, 学生认知能力维度中学生 学习收获因素得分最高, 即学生在本课程中所获得的专业 知识越多, 对今后学习的帮助价值越大, 学生兴趣有所提 高, 那么学生对课程的评价也就越高[10-11]。在研究生课 程教学中, 教师应该更加注重提高学生的学习兴趣和学习 积极性, 并且要考虑到应用型硕士和学术型硕士的差别, 应用型硕士应更多收获实践应用知识, 课程设置以实际应 用为导向, 以职业需求为目标, 以综合素养和应用知识与 能力的提高为核心, 注重培养学生研究实践问题的意识和 能力[12]。相反, 学术型硕士应更注重理论知识的传授, 重点培养学生从事科学研究创新工作的能力和素质。

2、考虑学生个人因素, 培养创新型人才

研究生教育对培育高层次人才、推动先进生产力和先 进文化、实现国家持续发展起到关键作用, 特别是创新人 才的培养如今已经上升到国家战略需要的高度, 因此, “因 材施教”在培养创新型人才过程中显得尤为重要 [13-14]。 调查数据显示, 学生的年级和硕士类别不同, 其认为各维 度在课堂上的重要程度不同, 因此要考虑到学生的年级等 外部因素, 在课程教学实施上区别对待, 以取得更好的课 程效果。就目前所调查的三所西南地区的高校而言, 存在 
部分课程有不同年级、不同硕士类别的学生一起上课的情 况, 这样的教学方式没有考虑到不同年级、性质的硕士研 究生的课程需求上的不同, 不利于培养出创新型人才。

3、积极参与课题讨论, 培养良好学习态度

课程是全日制硕士研究生培养的重要载体, 硕士研究 生作为专业课程学习的主体, 其对待专业课程的态度及其 采取学习行为, 能客观真实地反映出专业课程在一定程度 上满足了硕士研究生专业能力发展的需要 [15]。相较于本 科生而言, 硕士研究生的学习过程是更加独立自主的, 在 教学过程中, 任课教师、导师均是学习活动的客体, 研究 生才是学习活动的主体。受传统教育的影响, 在互动交流 方面大多数研究生表现得内玫且保守, 在学习过程中如果 研究生不善于提出自己的问题, 与教师、同学沟通, 课堂 学习效果会大打折扣, 为了提高研究生课程学习效果, 应 该鼓励研究生大胆尝试, 多与他人交流, 冲破传统思维的 束缚, 积极参与课堂讨论以及课题研究, 在思想碰撞中摩 擦出智慧的火花, 保持课堂氛围的活跃性, 在潜移默化中 培养自身良好的学习态度, 从而能够更有效地学习。

\section{致谢}

本文为教育部2018年度人文社科规划基金项目《“双 一流”视野下教师教育学科群及评价体系研究》的阶段性 成果之一;

本文为重庆师范大学2020年度研究生科研创新项目 《教师教育学科群特征及其优化策略研究——以师范院 校为例》的阶段性成果之一。

\section{参考文献}

[1] 马燕,张莉莉,邓丽姣.研究生导师指导满意度影响因素实证 研究——基于SEM模型 [J]. 重庆师范大学学报(社会科学 版),2020(03):68-76.

[2] 马燕,胡慧丽, 韩淑珍,陈星.研究生科研创新能力的影响因素 分析——基于 SEM 的实证研究 [J]. 现代教育管 理,2019(09):108-112.
[3] 顾艳丽. 学术型硕士研究生的专业课程认同研究[D].西南 大学,2019.

[4] 林丽萍.“因材施教”在研究生培养实践中的应用[J].江苏科 技信息,2018,35(25):64-66.

[5] 陈容,沈丽琴.基于结构方程模型的大学生网络获取性相关 信息行为影响因素分析 [J]. 预防医学情报杂 志,2020,36(11):1467-1474.

[6] 杜宝贵,唐纪航.高校学生科研诚信行为影响因素研究基于结构方程模型的分析 [J]. 辽宁工业大学学报(社会科学 版),2020,22(06):90-96.

[7] 王岳喜.论高校课程思政评价体系的构建 [J].思想理论教育 导刊,2020(10):125-130

[8] 徐燕敏,刘若泳. 全日制教育硕士专业学位研究生课程评价 因素探究—— 以A大学全日制教育硕士为例 [J].黑龙江教育 (高教研究与评估),2011(12):66-68.

[9] 付晨玉,徐慧玲.面向智能时代的经济金融拔尖创新人才培 养模式探索——以湖北经济学院财经高等研究院为例 [J]. 湖北经济学院学报(人文社会科学版),2020,17(11):118-120.

[10] 李锐,左精力,李微.场地坚向设计多元化课程考核评价体系 构建 [J].教育教学论坛,2020(46):198-199.

[11] 刘若泳,徐燕敏.影响硕士研究生课程评价因素探究—以 A大学教育学院为例 $[\mathrm{J}]$. 长春工业大学学报(高教研究 版),2011,32(02):51-53.

[12] 王敏.浅谈大学课程评价的影响因素[J].科技信息(学术研 究),2006(11):276-277.

[13] 朱孟青.MOOC背景下在线开放课程建设探究[J].决策探索 (下),2020(11):36-37.

[14] 方昕.基于 OBE理念的课程教学目标达成评价分析 [J].微型 电脑应用,2020,36(07):20-23.

[15] 龙冠丞.“双一流”战略下地方高校“一流学科”建设的困境与 突破[J].教书育人(高教论坛),2020(33):10-13. 